Preface

\section{Fecal Incontinence}

\author{
J. Marcus Downs, MD ${ }^{1}$ \\ ${ }^{1}$ Department of Colon and Rectal Surgery, Parkland and Presbyterian \\ Hospitals, Dallas, Texas \\ Clin Colon Rectal Surg 2014;27:83-84.
}

This issue of Clinics in Colon and Rectal Surgery is devoted to the care of our patients with fecal incontinence. Patients with this problem require all of the qualities we as surgeons ought to possess. We must spend time to really listen to our patient's story. This will guide our evaluation and allow us to choose the appropriate tests from the many discussed in this journal. We need to think critically. Many patients with incontinence have multiple factors at play. We need to integrate their story with our thoughtfully constructed evaluation and construct a treatment plan. Often this plan will have multiple options with no clear best choice, and this plan must be shared with our patients. Technical expertise is required, of course, and this is all the more challenging due to the disparate types of procedures treating fecal incontinence may entail. Finally, our care of incontinent patients needs to be more longitudinal than is required for our other patients with benign rectal conditions. In short, optimal care of our patients requires us to be complete surgeons.

Most of the readers of this journal have been caring for patients long enough to have seen many treatments come on the scene with a wave of enthusiastic adoption, too often followed by less vocal dissipation as these new procedures have failed to live up to their initial hope. Indeed, nearly every procedure discussed here is at some place on that curve. Recognition of this compels us to stay up to date, and this issue is presented in that light. This observation makes me comfortable in saying that our current practices will not be our future practices, but it gives me hope that new approaches will lead us to better care for our patients.

The authors of this issue are either associated with the Colon and Rectal Surgery Residency at Parkland and Presbyterian Hospitals, or are teaching faculty in other disciplines at UT Southwestern Medical School in Dallas, TX. I particularly wanted a broad range of specialty input, as the care we render will be improved the deeper our knowledge of normal continence and the multitudinous ways it can be derailed.

I would like to thank Dr. David Beck for inviting me to present the work of our community. His support throughout my surgical career is greatly appreciated.
Address for correspondence J. Marcus Downs, MD, Department of Colon and Rectal Surgery, Parkland and Presbyterian Hospitals, Dallas, TX
Issue Theme Fecal Incontinence; Guest Editor, J. Marcus Downs, MD
Copyright $\odot 2014$ by Thieme Medical Publishers, Inc., 333 Seventh Avenue, New York, NY 10001, USA. Tel: +1(212) 584-4662.
DOI http://dx.doi.org/ 10.1055/s-0034-1383900. ISSN 1531-0043. 